\title{
A EMERGÊNCIA DA ESCOLA NORMAL: formação de professoras e relações étnico-raciais
}

\author{
Raquel Amorim dos Santos \\ Taylon Silva Chaves \\ Sérgio Bandeira do Nascimento
}

\section{Resumo}

A pesquisa analisa a emergência da Escola Normal no período de 1938 a 1960 e sua proposição para a formação de professores e as relações étnico-raciais no município de Bragança, Pará. Pauta-se na abordagem qualitativa e caracteriza-se por uma pesquisa histórica-educacional com base em pressupostos da Nova História. Os dados apontam a educação e a religiosidade como pilares do processo formativo, ancorado na feminização do magistério que preparasse professoras como mulheres para o cuidado do lar e dos filhos, tementes a Deus e submissas aos seus maridos. Conclui-se que a criação da primeira Escola Normal no município de Bragança/PA, contribuiu para o desenvolvimento local, configurando-se como centro de formação escolar e espiritual, porém, desvencilhada da questão étnico-racial que permanecia ausente no debate político e educacional e nas propostas curriculares e formativas para a formação de professoras da Escola Normal.

Palavras-chave: escola normal; formação de professoras; relações étnico-raciais.

THE EMERGENCY OF NORMAL SCHOOL: women professors formation and ethnic-racial relations

\begin{abstract}
This research analyzes the emergence of the Normal School in the period from 1938 to 1960 and its proposition for women professors formation and ethnic-racial relations in the city of Bragança, Pará. It is based on a qualitative approach and it is characterized by historical-educational research based on the perspective of the New History. The results showed the education and religiosity as the foundation of the formative process, anchored in the feminization of the teaching that prepared women professors for housework and children care, to be fearful to God and submissive to their husbands. It concludes the relevance of the Normal School for local development, configuring itself as a center of school and spiritual formation, however, the ethnic-racial issue was not part of the proposal of education and professors formation, remaining absent in the political and educational debate, and in the curricular and formative proposals for women professors formation at Normal School.
\end{abstract}

Keywords: normal school; teacher education; ethnic-racial relations.

\section{LA EMERGENCIA DE LA ESCUELA NORMAL: formación docente y relaciones étnico-raciales}

Resumen

La investigación analiza el surgimiento de la Escola Normal en el período de 1938 a 1960 y su propuesta para la formación del profesorado y las relaciones étnico-raciales en la ciudad de Bragança, Pará, se basa en un enfoque cualitativo y se caracteriza por la investigación histórica. sobre la Nueva Historia. Los datos apuntan a la educación y la religión como pilares del proceso formativo, marcado por el proceso de feminización de la profesión docente que prepararía a las maestras, pero también a las mujeres para el cuidado del hogar y de los hijos, temerosas de Dios y sumisas a sus maridos. Se concluye que la Escola 
Normal contribuyó al desarrollo local, convirtiéndose en un centro de formación escolar y espiritual, sin embargo, desvinculado de la cuestión étnico-racial que permaneció ausente en el debate político y educativo y en las propuestas curriculares y formativas para la formación. de profesores de la Escola Normal.

Palabras clave: escuela normal; educación del profesorado; relaciones étnico-raciales.

\section{CONSIDERAÇÕES INICIAIS}

O artigo se propõe a investigar a emergência da Escola Normal e sua proposição para a formação de professoras e as possíveis implicações sobre a relações étnico-raciais entre os anos de 1938 e 1960 no município de Bragança, localizado no estado do Pará.

Em Bragança, instala-se a terceira Escola Normal do Pará no ano de 1938 por meio da criação do Instituto Santa Teresinha-IST sob a filosofia "Educar é não somente instruir. Instruir bem e preparar para a vida", conforme elaborou Dom Eliseu Maria Coroli, seu fundador, lema que se mantém até os dias atuais (NONATO DA SILVA, OLETO, 2010). A Escola Normal de Bragança-PA tinha como objetivo desenvolver uma formação docente com base na moral cristã, semelhante as demais escolas, influenciada pelos ideais educacionais e católicos europeus, o que, consequentemente, iria tornar a questão étnico-racial invisível (COELHO, 2006).

A invisibilidade da questão étnico-racial nos cursos de formação de professores é decorrente das teorias raciais da Europa do Século XIX que exerciam forte influência sobre o imaginário social e a educação da sociedade brasileira (SCHWARCZ, 1993; SANTOS, 2009, 2014). Essas teorias procuravam justificar biológica e ideologicamente a inferioridade do negro, acarretando em sua invisibilização nas relações sociais e, por conseguinte, nas propostas curriculares das escolas primárias, secundárias e das Escolas Normais, situação refletida atualmente na Educação Básica e no Ensino Superior (COELHO, 2006; GOMES, 2012) ${ }^{1}$.

Nesse sentido, buscou-se identificar os discursos sobre relações étnico-raciais e formação de professores contidos em fontes escritas e iconográficas, bem como os sentidos e significados sobre relações étnico-raciais na formação de professores no período de 1938 a 1960.

Para tanto, a pesquisa pauta-se na abordagem qualitativa, pois esta responde a questões muito particulares, como situações de aproximações sucessivas com a realidade, tornando-se, assim, uma combinação particular entre teoria e dados empíricos (MINAYO, 2001). Ademais, optou-se pelo método historiográfico baseado na perspectiva da Nova História que amplia temas, visibiliza novos sujeitos e explora novas fontes (BURKE, 1997).

Assim, problematiza-se a seguir a emergência da Escola Normal em Bragança-PA e a contribuição de Dom Eliseu Maria Coroli para o desenvolvimento da região amazônica, bem como algumas considerações finais acerca dos resultados do estudo.

\section{A ESCOLA NORMAL EM BRAGANÇA DO PARÁ}

A Escola Normal de Bragança-PA não se diferenciou muito acerca da inclusão do debate étnico-racial no currículo e nas práticas formativas da Escola Normal, porém, alcançou enorme notoriedade e assumiu grande influência sobre a educação e cultura locais. A Escola Normal de

1 Apesar da implantação das Escolas de Primeiras Letras em 1827 que demandou uma superficial preparação dos docentes (MORAIS, 2017), foi somente em 1961 - anos depois da criação das próprias Escolas Normais -, por meio da Lei de Diretrizes e Bases da Educação Nacional (LDB n. ${ }^{\circ}$ 4.024/61) que a Escola Normal foi institucionalizada no Brasil. Porém, mesmo estando na segunda metade do século XX, os cursos de formação de professores, em especial, do estado do Pará, continuavam a invisibilizar o sujeito negro em seus currículos e práticas formativas (COELHO, 2006; SANTOS, 2009, 2014; CHAVES, SANTOS, 2019, 2020; SILVA Jr. 2019).

Revista Teias v. $23 \cdot$ n. $68 \bullet$ jan./mar. 2022• 
Bragança surge no ano de 1938 por meio da chegada do padre Barnabita² Eliseu Maria Coroli, recém-chegado da Itália, escalado para assumir trabalhos nas terras amazônicas em uma lógica de "missões além-fronteiras" (NONATO DA SILVA, OLETO, 2010). Desde então, Eliseu Maria Coroli desempenhou um papel significativo, fazendo parte da própria história da educação e da formação de professores na região bragantina (COLARES, 1997).

\section{ELISEU MARIA COROLI: EDUCADOR E BISPO NA AMAZÔNIA}

Eliseu Maria Coroli nasceu em 1900 em Castelnuovo Val Tidone, pequena povoação da Província de Piacenza, na Itália e, cedo começou seus estudos para alcançar o sacerdócio. Quando chegou ao Brasil estava na condição de padre, mas logo seu trabalho o tornou notável perante a Igreja que o consagrou bispo e administrador da Prelazia do Guamá, atual Diocese de Bragança. Faleceu em 1982 em Bragança-PA (NONATO DA SILVA, OLETO, 2010). Atualmente está em processo de beatificação/canonização pela Igreja Católica, aguardando apenas a confirmação de um milagre testemunhado para tornar-se Santo Católico.

A nomenclatura Dom refere-se a sua consagração ao Bispado quando de sua proclamação como Bispo Prelado da Prelazia do Guamá, cargo importante na hierarquia eclesiástica da Igreja (NONATO DA SILVA, OLETO, 2010; SILVA et al, 2012). Porém, mesmo com as ascensões ministeriais, o Bispo nunca deixou de ser humilde e atencioso aos fiéis e cuidadoso nas obras de Deus (COLARES, 1997). Para a autora, Dom Eliseu Maria Coroli sempre mantinha um sorriso vívido por onde passava, sem, contudo, perder o rigor e a disciplina no ato de ensinar, demonstrando seu carinho pelas pessoas e zelo pelo trabalho eclesiástico.

Dom Eliseu era conhecido por sua dedicação no ato de ensinar, especialmente na maneira como tratava os alunos e as alunas e na forma como aplicava seus métodos de ensino, sempre com muito carinho e disciplina, agregando aos conhecimentos escolares a Fé, os preceitos morais e religiosos que considerava valiosos para uma formação cristã e para a vida (NONATO DA SILVA, OLETO, 2010). Mais que um bispo e educador, exemplo de cidadão e cristão, reconhecido pela fé, amor a Deus, cuidado pelas obras divinas e pelos irmãos e irmãs em Cristo: exemplo de vida, constituidor e constituinte da história de Bragança.

Por conseguinte, seu ministério e testemunho de vida é lembrando com muito afago e admiração pelas Irmãs da Congregação de Santa Teresinha e pelos moradores da região. Em cada lugar sua trajetória não passa despercebida, sendo respeitado e celebrado pelas autoridades eclesiásticas que administram a Diocese. $\mathrm{Na}$ escola que fundou e foi professor, o Instituto Santa Teresinha, verifica-se ainda hoje a influência de seus ideias e filosofia de ensino, especialmente na busca pela qualidade da formação escolar e espiritual dos alunos, educação pautada no lema da instituição, como citado anteriormente.

A seguir observa-se duas fotografias de Dom Eliseu Maria Coroli, preservadas no Memorial Dom Eliseu Maria Coroli, do Instituto Santa Teresinha-IST, de Bragança-PA, cuja proposição pode consistir justamente em apresentar uma imagem ilibada como Bispo e Educador na Amazônia.

2 A Congregação dos Padres Barnabitas foi instaurada no Brasil em 1904 e rapidamente se espalhou por várias regiões. Um dos seus objetivos era a disseminação do ensino religioso. Para essa Congregação tal ensino poderia garantir a formação de homens e mulheres íntegros, tementes a Deus e cidadãos exímios perante o Estado brasileiro (NONATO DA SILVA, OLETO, 2010; COLARES, 1997). 
Figura 01: Eliseu Maria Coroli.

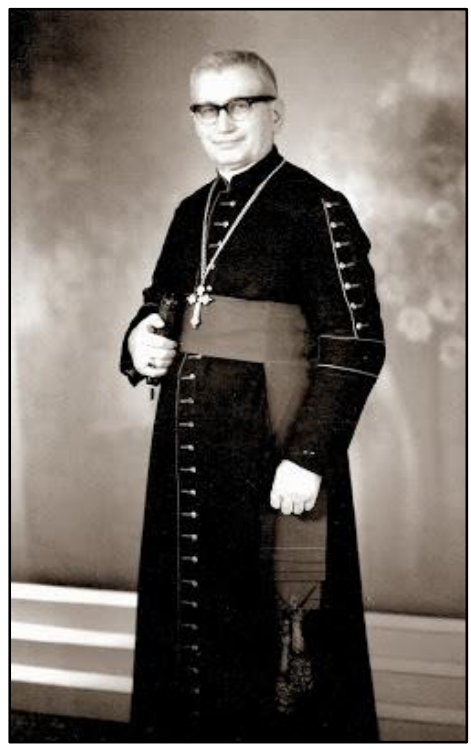

Fonte: acervo do Memorial

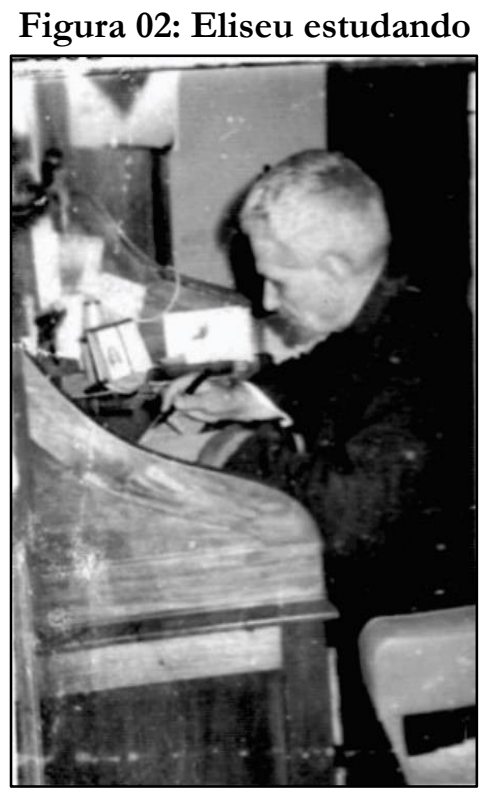

Fonte: acervo do Memorial.

$\mathrm{Na}$ figura 01 nota-se Dom Eliseu Maria Coroli com indumentária padrão para o cargo de Bispo Prelado, uma batina revestida de adereços que reportem à sua autoridade episcopal, como o crucifixo e a bata em sua cintura ${ }^{3 .}$ Como administrador da Prelazia, Dom Eliseu Maria Coroli vestiase de maneira adequada, valorizando a doutrina e as normas da Igreja católica. $\mathrm{Na}$ figura 02 observamo-lo em seu escritório pessoal, provavelmente preparando sermões e aulas de Matemática

3 A indumentária de Dom Eliseu Maria Coroli não representava apenas sua posição eclesiástica, mas seu poder e autoridade perante a sociedade bragantina e a administração pública (SILVA et al, 2012). 
e Religião ${ }^{4}$ para a Escola Normal. "Segundo ouvi dizer, antes da vinda para o Brasil, Pe. Eliseu estudou pedagogia como eminente Barnabita. Era natural que cheio de ardor juvenil, procurasse utilizar os conhecimentos pedagógicos" (COLARES, 1997, p. 32).

Desse modo, passava horas em meditação, dedicando-se aos estudos eclesiásticos, mas, também, aos estudos pedagógicos para ministrar as aulas e administrar a Escola Normal, demonstrando zelo e cuidado pela obra de Deus e pelo ensino dos alunos e alunas do Instituto Santa Teresinha. Segundo Nonato da Silva e Oleto (2010) Dom Eliseu se tornou um grande administrador apostólico e educador no município de Bragança por sua afeição ao ministério e bem-estar da população, fato que se refletia em seus trabalhos nos campos da educação, saúde, assistência social, evangelização etc. Consagrou-se em uma figura notável perante a sociedade bragantina pelo zelo da moral cristã, dedicação aos fiéis por meio de ensinamentos e do afeto e pela construção de boas relações entre a Igreja e a Administração Pública, sobretudo, nas relações e negociações políticas traçadas para o desenvolvimento de suas obras na região.

Diante disso, infere-se a relevância que Dom Eliseu Maria Coroli teve para a educação e desenvolvimento local de Bragança, realidade que culmina na própria história da cidade e da formação de professores. Por essa razão não se pode debater a formação docente sem considerar a atuação de Dom Eliseu Maria Coroli, principalmente por ter fundado uma instituição que mais tarde iria abrigar a terceira Escola Normal do Estado do Pará. Através desse novo empreendimento sua filosofia e ideias de ensino expandiram-se, superando os ensinos primário e secundário outrora ofertados, garantindo a disseminação da doutrina católica e dos seus ensinamentos por todos os lugares da Prelazia de Bragança-PA por meio de suas ações nos campos da educação e da saúde.

\section{INSTALAÇÃO DA ESCOLA NORMAL: ATO DE FÉ E POLÍTICA DE DESENVOLVIMENTO LOCAL}

A Escola Normal é instalada anteriormente à implantação do Instituto Santa Teresinha-IST que além de servir como espaço de formação de professores cedia lugar para o curso ginasial. No início do século XX o Brasil presenciava grandes transformações industriais nos países europeus e começou a incorporar o ideal de modernização como forma de desenvolvimento (BRITO, 2001). Diante dessa realidade Dom Eliseu procurou realizar uma política de empreendedorismo em Bragança que se vislumbra nas grandes obras construídas sob sua administração na Prelazia do Guamá $^{5}$ (NONATO DA SILVA, OLETO, 2010).

Antes de ser incorporada no IST, a Escola Normal funcionou em uma pequena casa que fora doada por um morador para abrigar os recém-chegados religiosos encarregados da administração da Prelazia do Guamá, atual Diocese de Bragança e, da evangelização das comunidades indígenas e rurais (COLARES, 1997). O prédio caracterizava-se por um estilo clássico dos modelos de residência europeus, de forma rudimentar, com cômodos que serviriam de alojamento para os padres. Localizava-se no centro da cidade ao lado de poucas casas, próxima

\footnotetext{
4 Consta-se que Dom Eliseu Maria Coroli ocupava, além da administração da Prelazia e do próprio Instituto Santa Teresinha, as cadeiras de Matemática e Religião no Ginásio e na Escola Normal.

5 Além do Instituto Santa Teresinha-IST, Dom Eliseu Maria Coroli realizou a construção do Hospital Santo Antônio Maria Zaccaria-HSAMZ, instituição que atende pessoas de várias regiões do Estado do Pará e, a criação da Quadra Poliesportiva Corolão, onde são realizados importantes jogos de futsal que envolvem a comunidade. Todas essas obras estão em pleno funcionamento na atualidade, o que pode expressar contribuições de Dom Eliseu Maria Coroli para o desenvolvimento local de Bragança-PA.
} 
DOI: $10.12957 /$ teias.2022.61878

à Igreja de Nossa Senhora do Rosário ${ }^{6}$ onde eram ministradas as missas. Em seguida a casa fora remanejada para as freiras e, mais tarde, para as aulas da Escola Normal.

Figura 03: $1^{\text {a }}$ Escola Normal de Bragança-PA.

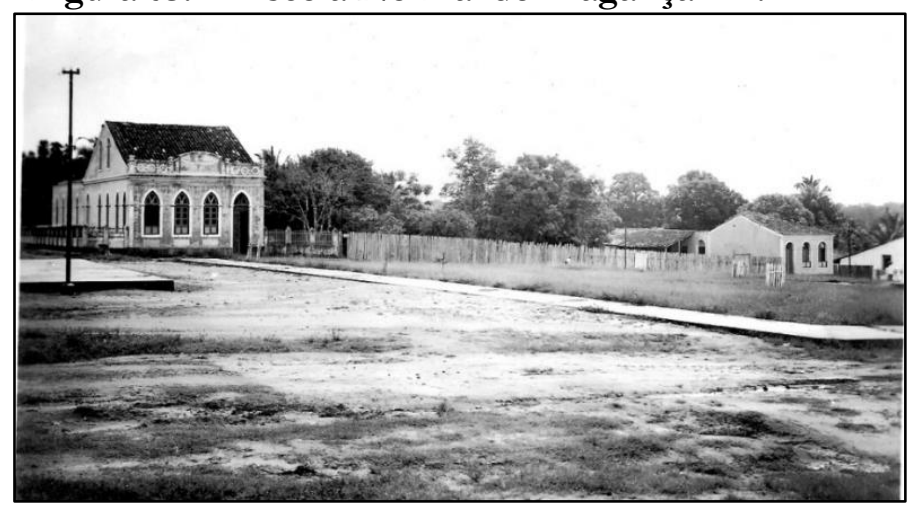

Fonte: acervo do Memorial.

Nesta pequena casa foram realizadas as primeiras aulas da Escola Normal que começaram em fevereiro de 1939 com 18 meninas e 01 menino, na modalidade internato, funcionando também como residência das Irmãs do Sagrado Coração de Jesus que colaboravam, junto com as Irmãs Preciosinas ${ }^{7}$ que vieram com Dom Eliseu da Itália, na organização da instituição e da Prelazia (NONATO DA SILVA, OLETO, 2010). Somente mais tarde as aulas foram remanejadas para o IST. Nesse ínterim Bragança começou a vislumbrar a modernidade no campo educacional e as famílias começaram a ter a oportunidade de inserir seus filhos em um Colégio em sua própria localidade, sobretudo as famílias mais abastadas (SILVA et al, 2012).

Como se observa no quantitativo de mulheres matriculadas, a Escola Normal de Bragança/-PA enfrentava um processo de feminização do magistério que estava ocorrendo nas demais escolas do Brasil. "A necessidade em educar as mulheres estava ligada à modernização da sociedade e ao processo de higienização da família, juntamente com a ideia da criação de um sentimento nacional vinculando a ordem e progresso [...]" (NOGUEIRA, SCHELBAUER, 2007, p. 79). Ademais, era uma oportunidade para a Igreja Católica formar professoras e catequistas que, com zelo e amor, cuidassem da alfabetização dos fiéis do interior da Prelazia (COLARES, 1997; NONATO DA SILVA, OLETO, 2010; SILVA et al, 2012).

Essa realidade refletia a concepção da mulher existente em uma sociedade patriarcal que limitava sua aparição pública, permitindo sua inserção em poucos ambientes de trabalho, preferencialmente, no magistério por considera-lo uma extensão das atividades domésticas (RABELO, MARTINS, 2006). Em decorrência dessa representação materna da mulher, esta restringia-se aos cuidados do lar e da família, considerando-se o fato de ser vista como um sujeito sentimental, portanto, desprovido de habilidades lógicas e racionais para trabalhos além da esfera doméstica (LOURO, 1999, 2007). Mesmo com sua admissão na carreira docente percebe-se a diferenciação no ensino entre homens e mulheres, como verificado no currículo para alunos e no currículo para alunas.

6 Atualmente intitulada Paróquia Catedral de Nossa Senhora do Rosário. Esta é a catedral sede da Diocese de BragançaPA onde são realizadas as principais missas e eventos da Igreja Católica.

7 Congregações religiosas originárias da Itália. Essas irmãs foram enviadas da Itália para o Brasil após Dom Eliseu Maria Coroli apresentar seu projeto de educação para Bragança-PA junto à Madre Superiora da Congregação e às autoridades episcopais (NONATO DA SILVA, OLETO, 2010; SILVA et al, 2012). 


\begin{abstract}
Nessa época, o currículo do estudo feminino era diferenciado do masculino: as moças se dedicavam à costura, ao bordado e à cozinha, enquanto os homens estudavam geometria. As mulheres professoras eram isentas de ensinar geometria, mas essa matéria era critério para estabelecer níveis de salário, portanto, reforçava-se com isso a diferença salarial. Assim, as mulheres tinham direito à instrução, mas essa instrução acentuava também a discriminação sexual [...]. Contudo, apesar do estudo passar a ser um direito garantido por lei, a maioria das mulheres não tinha acesso à instrução, com exceção daquelas que pertenciam às elites e às classes ascendentes, pois a segregação da mulher continuava presente na sociedade (RABELO, MARTINS, 2006, pp. 6170-6171).
\end{abstract}

Desse modo, a admissão da mulher nos cursos de formação de professores deu-se por meio de uma série de restrições que acarretaram na manutenção de preconceitos e de relações desiguais entre homens e mulheres. Acrescenta-se que além das diferenciações no ensino, no salário e nas condições de trabalho, aos homens competia o exercício de funções administrativas em cargos superiores e à docência em classes ginasiais, enquanto às mulheres cabia o ensino primário e raras chances de ascensão na carreira (NOGUEIRA, SCHELBAUER, 2007). Contudo, em BragançaPA essa realidade apresentava-se de modo um pouco diferente.

As professoras do curso primário e primeiras colaboradoras diretas de Monsenhor Eliseu, no Colégio Santa Teresinha [...] vieram para Bragança com suas famílias, lembradas em Bragança pela disciplina e rigor técnico. Por um lado, as professoras acreditavam no projeto educativo do religioso, dedicando-lhe tempo, trabalho e acompanhamento dos alunos. De outro, com a confiança de Coroli em se apoiar nos serviços de professoras leigas, colaboradoras na organização daquele ano escolar e na parceria obtida para que sua obra fosse levada adiante, até que a finalidade primordial do seu colégio se completasse: "preparar jovens, que levando uma vida consagrada a Deus, ajudassem a evangelização de sua terra” (SILVA et al, 2012, p. 102).

Depreende-se que as professoras leigas do Instituto Santa Teresinha-IST eram muito valorizadas por Dom Eliseu Maria Coroli, sendo consideradas colaboradoras e profissionais rígidas com o trabalho educativo. Além das freiras que colaboravam significativamente com o bispo nas atividades ministeriais e escolares, a exemplo de viagens missionárias e as atividades da Escola normal e do IST, professores leigos eram contratados do mesmo modo, pois apesar de ser uma instituição de cunho religioso tornou-se necessário equipará-lo aos cursos primário e secundário da capital e ajustá-lo ao ideal de Estado laico introduzido com a instauração da República ${ }^{8}$ (COLARES, 1997; NONATO DA SILVA, OLETO, 2010; SILVA et al, 2012).

As primeiras professoras da Escola Normal de Bragança-PA haviam vivenciado uma concepção rígida e tradicional de educação conforme os moldes da época. Consequentemente, as primeiras alunas teriam uma formação semelhante, acrescentada a ideia de uma educação cristã (NONATO DA SILVA, OLETO, 2010). Durante esse período as alunas aprendiam técnicas e

\footnotetext{
8 É interessante atentar para o fato de que a proposta de formação docente e educacional estava diretamente atrelada a proposta de propagação da fé cristã e do catolicismo na região. Por isso, verifica-se a coexistência de professoras e professores religiosos e leigos que lecionassem os preceitos divinos e as normas do Estado (COLARES, 1997; NONATO DA SILVA, OLETO, 2010; SILVA et al, 2012). Vale ressaltar que um dos pressupostos da Republica é a laicidade do ensino, processo de secularização da educação. Nesse caso há no plano legal a separação entre o Estado e a Igreja. Talvez aqui esteja uma chave muito importante que é justamente a tentativa de setores do catolicismo em retomar espaços como a educação, historicamente vinculada à igreja e seus propósitos (VILLELA, 1992, 2002).
} 
métodos específicos de ensino que contribuíssem para a alfabetização e catequização da população bragantina, pautados no rigor da moral e na atenção aos preceitos divinos, orientados pela fé e pelos ideais do Estado e da Nação (COLARES, 1997; SILVA et al, 2012).

O início da Escola Normal foi marcado pelo estabelecimento de uma pedagogia tradicional ${ }^{9}$, responsável pela criação de uma atitude de recepção do saber instituído, mas que também procurava o desenvolvimento integral e a participação ativa dos alunos nos processos de aprendizagem (LUCKESI, 2010). Essa pedagogia se relacionava perfeitamente com a proposta educacional de Dom Eliseu, eminentemente cristã e, portanto, rigorosa no sentido do atendimento dos preceitos divinos, mas, também, preocupada com o desenvolvimento espiritual e escolar dos alunos e com a formação cristã e profissional que centralizasse o ensino religioso (NONATO DA SILVA, OLETO, 2010; SILVA et al, 2012; COLARES, 1997).

A proposta educacional de Dom Eliseu para o IST e para a Escola Normal de BragançaPA seguia quatro direções, quais sejam: catequese, educação escolar, assistência hospitalar e evangelização dos índios (NONATO DA SILVA, OLETO, 2010). A catequese baseava o trabalho pedagógico, pois era indispensável para a formação cristã desejada pela Prelazia. A educação escolar funcionava como subsídio para a construção da fé a partir do ensinamento das Escrituras Sagradas. A assistência hospitalar garantia um pouco de qualidade de vida para os munícipes. E a evangelização, inclusive de indígenas, possibilitava a constituição do conhecimento da Igreja sobre as comunidades que professavam outras crenças e credos.

Figura 04: Dom Eliseu Maria Coroli realizando a Coroação de Nossa Senhora no IST com alunos do Ginasial e da Escola Normal.

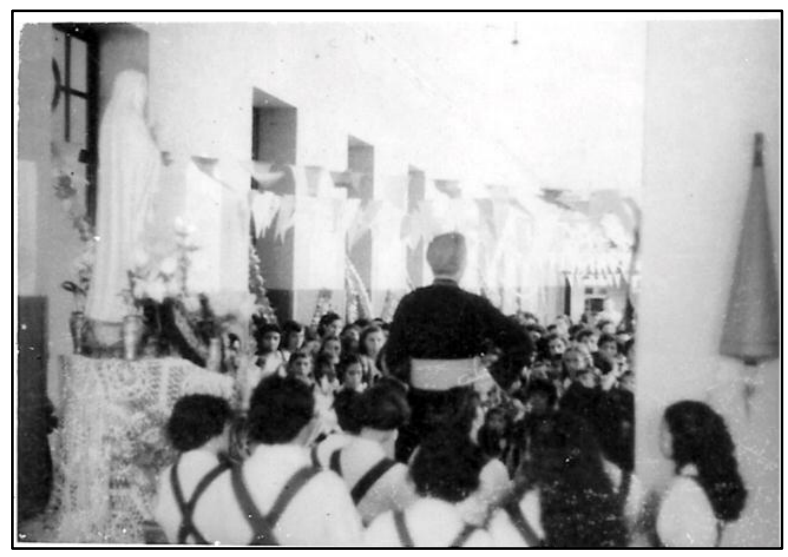

Fonte: acervo do Memorial.

9 “A denominação 'concepção pedagógica tradicional' ou 'pedagogia tradicional' foi introduzida no final do século XIX com o advento do movimento renovador que, para marcar a novidade das propostas que começaram a ser veiculadas, classificou como 'tradicional' a concepção até então dominante. Assim, a expressão 'concepção tradicional' subsome correntes pedagógicas que se formularam desde a Antiguidade, tendo em comum uma visão filosófica essencialista de homem e uma visão pedagógica centrada no educador (professor), no adulto, no intelecto, nos conteúdos cognitivos transmitidos pelo professor aos alunos, na disciplina, na memorização. Distinguem-se, no interior dessa concepção, duas vertentes: a religiosa e a leiga" (verbete elaborado por Dermeval Saviani). (Disponível:<http://www.histedbr.fe.unicamp.br/navegando/glossario/verb_c_concepcao_pedagogica_tradicional. htm>. Acesso: 01 de abril de 2020). 
$\mathrm{Na}$ fotografia destaca-se Dom Eliseu Maria Coroli em solenidade no Instituto Santa Teresinha-IST. Na ocasião o bispo realizava a Coroação de Nossa Senhora ${ }^{10}$ no salão de missas e eventos do Colégio com a participação da comunidade, especialmente dos alunos e alunas das turmas do Ginásio e da Escola Normal. Esta solenidade se refere às duas primeiras direções da proposta educacional de Dom Eliseu para o IST e para a Escola Normal: a catequese e a educação escolar. Por meio da relação entre fé e saberes terrenos (seculares) acreditava-se ser possível a realização de uma formação integral que correlacionasse os preceitos divinos, os ideais da República e os conhecimentos necessários à vida em sociedade. Em outras palavras, essa relação possibilitaria uma preparação para a vida (COLARES, 1997; SILVA et al, 2012).

Ademais, a fotografia evidencia a autoridade de Dom Eliseu Maria Coroli na Igreja Católica, no Instituto Santa Teresinha, na Escola Normal e, consequentemente, no município de Bragança, especificamente quando se observa uma posição de destaque de Dom Eliseu na abertura da Coroação, denotando sua condição elevada na hierarquia eclesiástica (COLARES, 1997). Também se verifica uma padronização nos uniformes das alunas, fato que revela a rigorosidade do ensino na primeira metade do século XX, onde o alunado, mormente o público feminino, deveria trajarse de acordo com os padrões morais instituídos e em respeito à instituição escolar e aos professores e mentores educacionais (VILLELA, 1992, 2002).

Nesse sentido, depreende-se que a Escola Normal não funcionou apenas como um centro de preparação técnica para o trabalho docente, mas igualmente como espaço de reprodução dos preceitos religiosos/morais da doutrina católica no sentido de ampliar a fé cristã por meio dos novos professores que iriam atuar na alfabetização e na catequização da população em diferentes localidades de domínio da Igreja, convertendo-os a Cristo e aos dogmas católicos. Desse modo, mais que um lugar de formação profissional a Escola Normal de Bragança-PA fora um lugar de difusão dos interesses da Prelazia, da Igreja e de Dom Eliseu Maria Coroli (SILVA et al, 2012; NONATO DA SILVA, OLETO, 2010; COLARES, 1997).

A figura abaixo mostra um registro peculiar de Dom Eliseu Maria Coroli com algumas formalistas e enfermeiras do Hospital Santo Antônio Maria Zaccaria-HSAMZ em uma de suas visitas realizadas com a finalidade de supervisionar os trabalhos desenvolvidos pelas alunas e funcionários. Assim como ocorria no Instituto Santa Teresinha-IST as alunas eram devidamente uniformizadas sob uma rígida educação escolar, moral e espiritual. Essas visitas de Dom Eliseu Maria Coroli eram corriqueiras e demonstravam sua preocupação sobre o ensino, procurando estar ciente dos processos formativos e de prestação de serviços disponibilizados em seus empreendimentos (SILVA et al, 2012). Segundo Colares (1997), o bispo costumava agir com afinco, sempre entusiasmado e com um brilhante sorriso na relação com os outros ${ }^{11}$.

\footnotetext{
10 A Coroação de Nossa Senhora é uma festividade tradicional católica que ocorre todos os anos no último dia do mês de maio em Bragança-PA sob responsabilidade da Diocese (evento municipal) e das Paróquias (eventos paroquiais) e organização de uma determinada escola pública ou particular, selecionada anualmente através de sorteio realizado pela administração da Igreja.

11 Destaca-se que Dom Eliseu é lembrado pelas Irmãs do Sagrado Coração de Jesus pelo seu sorriso todas as vezes que se comunicava com alguém, principalmente com alunos e alunas, demonstrando carinho e cuidado por seus fiéis e aprendizes (COLARES, 1997; NONATO DA SILVA, OLETO, 2010).
} 
DOI: $10.12957 /$ teias.2022.61878

Figura 05: Dom Eliseu Maria Coroli, alunas, formalistas e enfermeiras do Hospital Santo Antônio Maria Zaccaria-HSAMZ, criado para garantir assistência hospitalar à população bragantina.

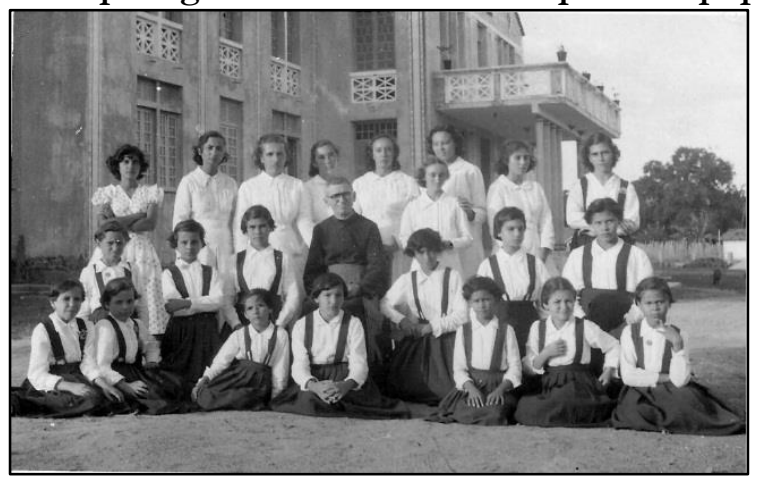

Fonte: acervo do Memorial.

No tocante à assistência hospitalar, terceira direção da proposta educacional de Dom Eliseu Maria Coroli, destaca-se que "Além do Colégio Santa Teresinha, duas outras obras da ação de D. Eliseu Coroli ganharam notoriedade e relevância: a Maternidade Nossa Senhora da Divina Providência e o Hospital Santo Antônio Maria Zaccaria [...]" (SILVA et al, 2012, p. 106). Inaugurados em 1952, o Hospital e a Maternidade serviram como instrumentos para a concretização do desejo do bispo em garantir assistência hospitalar aos moradores (COLARES, 1997), empreendimentos significativos para a região bragantina ${ }^{12}$, razão pela qual atribui-se papel significativo à atuação de Dom Eliseu Maria Coroli no desenvolvimento local.

A realização desses empreendimentos compunha a agenda ministerial, mas também a agenda política de Dom Eliseu, pois sua instalação beneficiaria a população e, simultaneamente, consolidaria o poder da Igreja no município de Bragança (SILVA et al, 2012). A partir de suas relações políticas com a administração pública estadual e com os poderes locais, Dom Eliseu trouxe para Bragança a modernidade, tornando a região da Amazônia paraense desenvolvida em termos educacionais e de assistência à saúde, considerando os padrões da época. Isso supõe que as ações do bispo não eram elaboradas em um campo neutro, ao contrário, eram realizadas de maneira sistemática a fim de garantir que os interesses da Prelazia fossem alcançados ${ }^{13}$.

Nesse sentido, pode-se dizer que as implantações do Instituto Santa Teresinha, da Escola Normal, da Maternidade Nossa Senhora da Divina Providência, do Hospital Santo Antônio Maria Zaccaria, entre tantas outras obras, configuram-se como uma estratégia de desenvolvimento local e de expansão dos domínios da Prelazia. Para completar seu propósito, Dom Eliseu Maria Coroli investiu na evangelização dos índios que pertenciam ao território da Prelazia, comunidades

12 Até então a assistência hospitalar sistematizada da população bragantina limitava-se à capital do Estado do Pará, Belém, município relativamente distante de Bragança, fato que dificultava a realização de procedimentos médicos básicos e partos seguros. Com a implantação do Hospital e da Maternidade essa realidade mudou, permitindo aos munícipes um atendimento de qualidade (COLARES, 1997).

13 Convém ressaltar que nem sempre as ações do bispo eram vistas de forma positiva, especificamente em alguns canais de comunicação da imprensa local, a saber: “[...]. Em 1944, o Grêmio Bragantino, fundado em 1933 e liderado pelos bragantinos Armando Bordallo da Silva, Bolívar Bordallo da Silva, Luiz Paulino dos Santos Mártires e Franco Mártires, da geração da famosa Revista Bragantina, iniciou uma campanha contra o propósito do bispo Coroli. O caso era o da construção do muro na parte externa do Colégio Santa Teresinha e resultou na acusação de que Dom Eliseu obrigara os moradores do quarteirão vizinho ao prédio da escola a venderem suas moradias por um valor abaixo do preço de custo, além de que tal construção atentaria contra a estética da cidade" (NONATO DA SILVA, OLETO, 2010, p. 23). Apesar das críticas, a Prelazia obteve sucesso na empreitada do muro. Contudo, essas informações comumente são esquecidas a fim de manter intacta a índole de Dom Eliseu Maria Coroli entre os bragantinos.

Revista Teias v. $23 \cdot$ n. 68 • jan./mar. 2022 • 
longínquas do centro da cidade que demandavam longas e exaustivas viagens sob a justificativa de levar-lhes a mensagem da Cruz e o conhecimento de Deus para que alcançassem perdão e o esclarecimento das coisas terrenas e celestiais (COLARES, 1997).

A evangelização dos índios, quarta e última direção da proposta educacional de Dom Eliseu Maria Coroli para o IST e para a Escola Normal de Bragança-PA, apesar de ser uma atitude pautada em princípios de caridade e salvação pela aceitação do Evangelho, configura-se enquanto uma tentativa de imposição cultural (SILVA et al, 2012) ${ }^{14}$. Segundo Hall (2001) a imposição cultural consiste na dominação intelectual de determinado grupo sobre outro e na homogeneização da identidade. Para Bourdieu (2010), nas relações sociais é muito comum que os grupos dominantes exerçam poder sobre as identidades dos grupos historicamente estigmatizados em uma tentativa de manter a ordem vigente.

Nesse sentido, o grupo que se constituiu hegemônico culturalmente impõe sua forma de vida e organização social sobre aqueles historicamente subalternizados (GOMES, 2012). Por essa razão é que se compreende que as incursões de Dom Eliseu nas comunidades indígenas constituíram-se como tentativas de imposição cultural, uma vez que a Igreja os considerava desprovidos de civilidade e cultura. Assim sendo, as práticas de evangelização e catequização da Prelazia não agregavam conhecimentos da cultura dos índios, ao contrário, sobrepunham-se, ocasionando possíveis perdas de identidade (NONATO DA SILVA, OLETO, 2010) ${ }^{15}$.

Figura 06: Dom Eliseu Maria Coroli em visita à comunidade indígena.

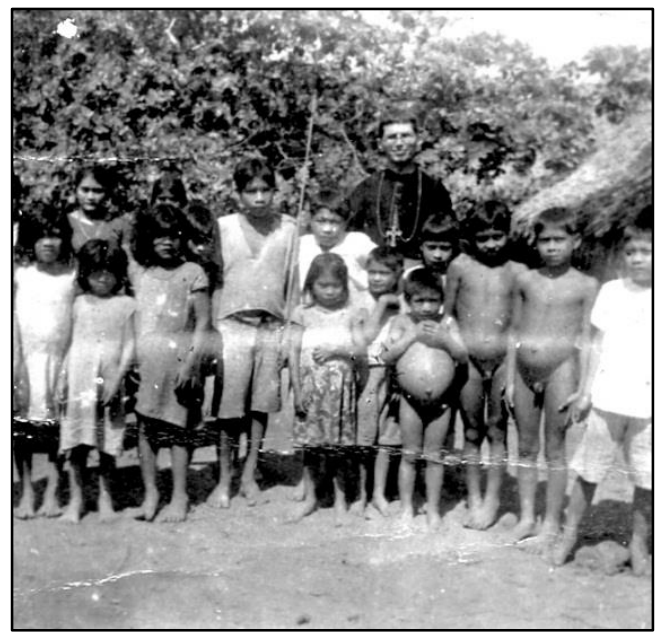

Fonte: acervo do Memorial.

A fotografia retrata uma das inúmeras viagens de Dom Eliseu Maria Coroli ao interior da Prelazia, especialmente às comunidades indígenas outrora existentes. Em decorrência de sua habilidade em comunicar-se com diferentes grupos Dom Eliseu era recebido em muitas aldeias, participando da dinâmica social e cultural destas, relacionando-se com variadas faixas etárias, inclusive crianças, como observa-se na imagem. Mas, as relações com as comunidades indígenas, aparentemente amigáveis, não eram estabelecidas de forma horizontal. Ao contrário, constituíam- 
se em relações de poder em que a figura eclesiástica e o poder da Igreja estavam acima das tradições e costumes desse grupos étnico-raciais, instituindo uma imposição cultural.

Com efeito, as comunidades indígenas foram classificadas como povos que precisavam da educação e da cultura estabelecidas pela Igreja, pois eram supostamente desamparadas pela civilização (SILVA et al, 2012). Não obstante, os padres barnabitas, na "missão além-fronteiras" na Amazônia, estabeleceram como propósito "[...] salvar os caboclos de toda forma de analfabetismo, principalmente do conhecimento de Deus e da religiosidade" (NONATO DA SILVA, OLETO, 2010, p. 26), construindo uma representação equivocada acerca das comunidades indígenas e tradicionais, destituindo-as de qualquer valor cultural, simbólico ou político (GOMES, 2012), acarretando na imposição cultural (HALL, 2001) ${ }^{16}$.

Esse empreendimento de Dom Eliseu não só recebeu o apoio da Prelazia como adquiriu o sufrágio das forças políticas locais, estaduais e mesmo federal, sobretudo, dos prefeitos e interventores, bem como da própria sociedade local ${ }^{17}$. Isso porque a ideia de evangelização dos índios da região não beneficiaria apenas a Prelazia, mas toda a cidade de Bragança, pois, por meio desse projeto seria possível garantir a uniformidade entre os diferentes grupos culturais e manter a ordem vigente, principalmente ao considerar que Dom Eliseu procurava atender tanto os interesses religiosos quanto os políticos (NONATO DA SILVA, OLETO, 2010).

Nesse sentido, "[...] o relacionamento entre a Igreja e a Prefeitura se dava de forma cordial, notando-se uma deferência especial de um poder para com o outro, já que se pretendia elevar o nível cultural do município e a sua cultura a partir do ambiente educacional [...]" (NONATO DA SILVA, 2010, p. 13). Em decorrência da preocupação mútua do governo local e da Igreja, Dom Eliseu encontrou condições favoráveis para suas empreitadas, alcançando enorme prestígio entre munícipes e políticos. Foi nessa direção que Dom Eliseu se tornou pioneiro na formação de professores na região, influenciando muitas gerações e diferentes governos.

Nesse contexto, em 1939 os padres barnabitas decidiram construir o Instituto Santa Teresinha, tendo à frente desta empreitada Dom Eliseu Maria Coroli, idealizador e fundador do IST. No ano de 1940 fizeram o lançamento da Pedra Fundamental, solenidade tradicionalmente católica realizada no início de qualquer obra predial da Igreja Católica, que consistiu em uma celebração com a introdução de uma Bíblia no subsolo da nova construção, simbolizando a Palavra de Deus como base da instituição, das práticas educativas e formativas para crianças, jovens e adultos. Essa festividade contou com a participação de muitos bragantinos e de alguns políticos, o que denota a influência e o prestígio de Dom Eliseu Maria Coroli em Bragança-PA.

$\mathrm{Na}$ fotografia a seguir observa-se Dom Eliseu introduzindo a Pedra Fundamental (Bíblia) no subsolo onde seria construído o IST na presença de alunas, alunos, comunidade local e, notadamente, de Augusto Corrêa, prefeito de Bragança-PA na ocasião. Essa solenidade confirma, novamente, a influência de Dom Eliseu na região e junto às autoridades locais, recebendo o prestígio, a admiração e as concessões das administrações municipais na concretização de seus

16 Imposição cultural, de acordo com Hall (2001), consiste na tentativa de padronizar a cultura instituída pelos grupos dominantes àqueles considerados desprovidos de civilidade e conhecimento. Segundo Bourdieu (2010) esse conceito pode relacionar-se à noção de hegemonia cultural, caracterizada também pela tentativa de impor, pela força ou violência simbólica, uma cultura sobre a outra.

17 Dom Eliseu comumente caia nas graças do povo, da administração pública estadual e dos poderes locais, principalmente pela cordialidade com que tratava os interesses da Prelazia e do município junto ao Poder Público. Por meio de boas relações com o Poder Público, Dom Eliseu conseguiu desenvolver muitos trabalhos e empreendimentos em Bragança, como fora na implantação do Instituto Santa Teresinha e na criação do Hospital Santo Antônio Maria Zaccaria (COLARES, 1997). 
projetos (COLARES, 1997; NONATO DA SILVA, OLETO, 2010; SILVA et al, 2012) ${ }^{18}$. Sendo assim, mais que uma autoridade eclesiástica, o bispo constituía paulatinamente seu papel político na construção da identidade cultural da região.

Figura 07: Lançamento da pedra fundamental de construção do prédio do IST em julho de 1940, tendo ao lado direito de Dom Eliseu o então prefeito Augusto Corrêa.

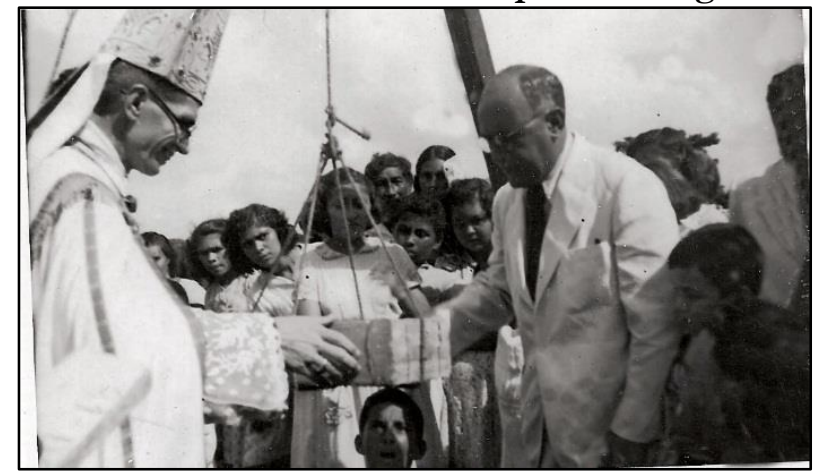

Fonte: acervo do Memorial.

O Instituto Santa Teresinha se constituiu como um marco histórico para o município de Bragança e para a formação de professores no Pará, pois sediou a terceira Escola Normal do Estado, bem como a oferta dos ensinos primário e secundário (SILVA et al, 2012). Naquela época era necessário que as Escolas Normais no Brasil possuíssem escolas anexas para a experimentação dos métodos e técnicas de ensino ${ }^{19}$ (TANURI, 2000; VILLELA, 1992, 2002). Nesse sentido, o IST foi construído com o intuito de garantir a equiparação desses níveis ao da Escola Normal a fim de atender às normas educacionais vigentes (NONATO DA SILVA, OLETO, 2010). Apesar de alguns infortúnios ${ }^{20}$ o IST foi inaugurado em 1944 com a celebração da formatura da primeira turma de normalistas da Escola Normal (COLARES, 1997).

18 Existem evidências de que a autorização de construção do IST no centro da cidade fora uma das concessões do poder municipal à Dom Eliseu Maria Coroli graças à sua simpatia e articulação política, comprando um terreno em uma das áreas mais importantes da cidade (SILVA et al, 2012).

19 Com a substituição do método Lancaster ou método de ensino mútuo - comumente utilizado nas Escolas de Primeiras Letras - pelo método do ensino intuitivo de Pestalozzi - adotado após a consolidação e expansão das Escolas Normais no final do século XIX - a observação passou a ser uma premissa/exigência para a formação de professores, pois a aprendizagem do ensino intuitivo ocorreria somente por meio de experiências sensoriais (TANURI, 2000; VILLELA, 1992, 2002; MORTATTI, 2006). Ademais, a aprendizagem dos métodos e técnicas de ensino tradicionais, como a memorização de conteúdos e a aplicação de exercícios, seria adquirida mediante a observação de práticas pedagógicas, docentes e escolares realizadas em escolas anexas às Escolas Normais. No caso de Bragança-PA, especificamente, acrescenta-se o ensino religioso como eixo centralizador do trabalho educativo, expresso no hábito da leitura e ensinamento de textos sagrados (COLARES, 1997; SILVA et al, 2012).

20 No processo de construção do IST o Exército Brasileiro se apropriou do Colégio para a instalação de uma base militar durante a Segunda Guerra Mundial. Esse episódio causou sérios problemas para os intentos de Dom Eliseu e dos padres barnabitas que sonhavam com a implantação do instituto. Mas com afinco e dedicação, o bispo tentou contornar a situação. Em 1943, após acordo com o Comando do Exército, o IST fora devolvido à Prelazia de Bragança e aos padres barnabitas. Entretanto, os militares saem definitivamente do prédio apenas em 1945 com o fim da Grande Guerra (NONATO DA SILVA, OLETO, 2010). 
Figura 08: Prédio do IST na data de sua inauguração, 1944.

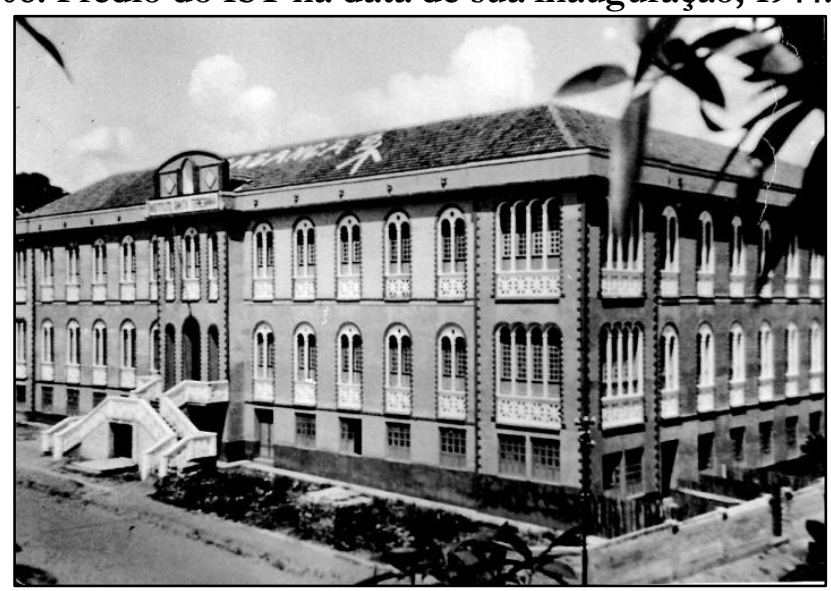

Fonte: acervo do Memorial.

Observa-se na fotografia o Instituto Santa Teresinha no ano de sua inauguração, em 1944. “[...] Segundo Bolívar Bordallo da Silva, o edifício era um prédio 'de 3 pavimentos, de construção sólida e estilo gótico, com capacidade para 300 alunos' [...]” (SILVA, 1954 apud SILVA et al, 2012, p. 105). Destarte, apesar de algumas mudanças estruturais, como a construção de outros pavimentos e de muros ao entorno, o edifício mantém as mesmas características de sua estética original, abrigando atualmente uma grande quantidade de turmas, desde a Educação Infantil até o Ensino Médio, com adaptações de acessibilidade e instalação de recursos tecnológicos. Desse modo, percebe-se a sua relevância social para a região, ampliando sua oferta escolar e consolidandose enquanto renomada instituição de ensino.

Figura 09: Quadro de fotos da primeira turma de normalistas da Escola Normal de Bragança-PA.

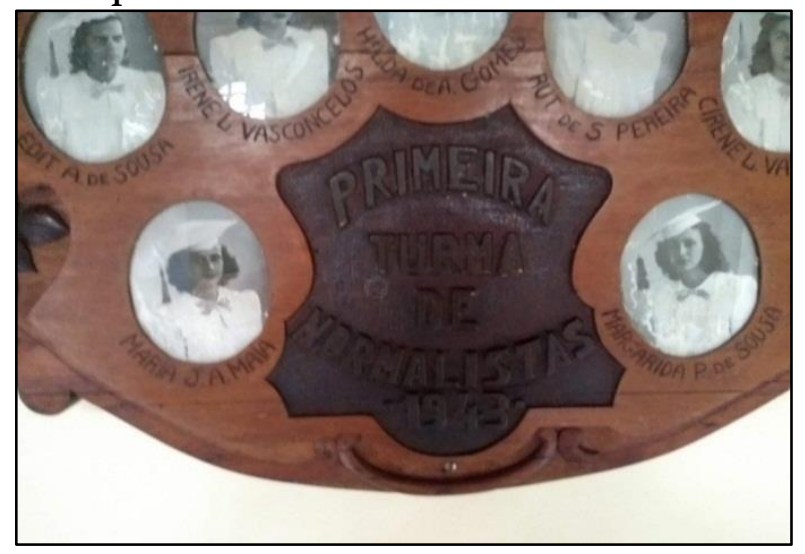

Fonte: acervo do Memorial.

Nesta fotografia observa-se um quadro de fotos da primeira turma de normalistas da Escola Normal de Bragança-PA (1943) que abrilhantaram a inauguração do IST no ano de 1944. Destacase que a partir das fotos inseridas no quadro vê-se mulheres jovens, uniformizadas de forma adequada ao contexto moral da época: cobrindo o corpo, demonstrando sua contrição e devoção cristã. Acrescenta-se que mais que professoras e catequistas, estas mulheres foram formadas para ser mães e esposas, submissas ao homem, voltadas ao cuidado do lar e do marido e à educação dos 
filhos, fato que contribuiu para a disseminação dos ideais da República que consistiam especialmente na manutenção da ordem vigente ${ }^{21}$.

Segundo Louro (1999) essas mulheres introduzidas no contexto educacional e, posteriormente, no mercado de trabalho, tinham permissão para instruir-se dentro de certos limites, pois a ordem natural - na verdade social - deveria permanecer intacta. Ou seja, diante de um momento histórico significativo para as mulheres, aonde teriam a chance de estudar e trabalhar, estas deparam-se com as imposições e normativas culturais baseadas em uma sociedade patriarcal, onde a figura feminina não poderia ascender e, quando autorizada a ingressar no espaço público, continuava tolhida, forçada a vestir-se de forma adequada, a aprender o que lhe for conveniente e atuar em ambientes não dominados pelo homem.

Dessa forma, entende-se que a Escola Normal de Bragança-PA se insere em um paradoxo: de um lado permite a instrução e a formação de professoras e catequistas; por outro lado reproduz a ordem vigente e molda estas mulheres de acordo com os padrões segregacionistas entre homens e mulheres, permitindo-lhes o magistério, mas sem dar-lhes a liberdade e autonomia devidas. Nesse sentido, depreende-se que a Escola Normal de Bragança-PA foi ao mesmo tempo um marco para o desenvolvimento local e um espaço de reprodução da sociedade patriarcal estabelecida no Brasil e estendida a todos os espaços sociais (FRANCA, FRANÇA, 2011; SOUSA, 2011; LOBATO, 2010; LOURO, 1999, 2007).

Depois de a Escola Normal funcionar em uma pequena casa as primeiras normalistas participaram de uma bela formatura na mais nova construção da Prelazia sob a administração de Dom Eliseu, evento que ratificou suas intenções com a evangelização, educação escolar e desenvolvimento local (NONATO DA SILVA, OLETO, 2010). A partir disso se consolidava uma educação pautada na moral cristã que serviria como sustentáculo da sociedade, pois, apesar do caráter técnico-profissional, a Escola Normal de Bragança-PA não se desvincularia do modo eminentemente religioso do ensino que suplantava essas escolas na sociedade da época.

Diante desse percurso histórico da formação de professores no Brasil se percebem os impasses no campo da educação, que avançava ou retrocedia à medida que o Poder Público desempenhava determinado grau de ação. Em toda a história verifica-se que a formação docente não recebeu o devido tratamento, ficando em segundo plano na agenda política dos diferentes governos (SAVIANI, 2009, 2006; GATTI, 2010, 2016). Nessa direção, a questão étnico-racial esteve despercebida, na verdade, ausente dos currículos oficiais e das práticas formativas dos cursos de formação de professores (GOMES, 2012; SANTOS, 2014; COELHO, 2006).

As fotografias do Memorial Dom Eliseu Maria Coroli revelam indiretamente a ausência do Poder Público na garantia da formação de professores e a inexistência da questão étnico-racial na proposta de educação e de formação docente de Dom Eliseu Maria Coroli. Essa realidade se expressa na criação de uma instituição de ensino e da Escola Normal pela Igreja Católica, especificamente pela Prelazia/Diocese de Bragança-PA e não pela Administração Pública Municipal; e no registro de viagens missionárias às comunidades indígenas, sem, contudo, explorar e divulgar a diversidade cultural desses grupos étnico-raciais, evidenciando apenas a atuação de Dom Eliseu Maria Coroli e de sua equipe missionária na educação e catequização de povos "desprovidos de civilidade e cultura" ou dos "caboclos" da Amazônia.

No caso da Escola Normal de Bragança-PA, assim como ocorria nas demais Escolas Normais brasileiras, a questão étnico-racial não recebia o devido tratamento, considerando que essa

21 Durante a República o papel da mulher adquire uma dimensão social na educação dos filhos que se estende, paulatinamente, ao mercado de trabalho. No entanto, em todos os casos, deveria ser submissa ao homem, mantendose a ordem vigente de família e sociedade (NOGUEIRA, SCHELBAUER, 2007).

Revista Teias v. 23 • n. 68 • jan./mar. 2022• 
temática não fazia parte das pautas políticas e educacionais dos governos. O único vestígio acerca das relações étnico-raciais observado nas fontes foi a intenção de Dom Eliseu Maria Coroli em evangelizar os índios da região (COLARES, 1997; MAUÉS, 1999; NONATO DA SILVA, OLETO, 2010; SILVA et al, 2012). Conforme Nonato da Silva e Oleto (2010) a evangelização dos índios era um dos objetivos do bispo quando chegou em Bragança-PA, pois havia elevado índice de analfabetismo entre as comunidades do interior e, além disso, tê-los convertidos ao catolicismo facilitaria o desenvolvimento das ações e missões da Igreja Católica.

Segundo Silva et al (2012) as intenções de Dom Eliseu Maria Coroli na alfabetização e catequização foram consideradas louváveis pela administração pública, Prelazia/Diocese e sociedade bragantina, pois trouxeram benefícios para a educação e o desenvolvimento local. No entanto, também foram questionadas por acarretarem no silenciamento da cultura popular e na imposição dos dogmas e da cultura da Igreja Católica sobre os povos indígenas (MAUÉS, 1999). Apesar dos esforços do bispo no melhoramento da região, a evangelização dos índios contribuiu para a construção de uma representação estereotipada desses sujeitos, especialmente pelo uso do termo "caboclos" como se fossem aculturados e destituídos de civilização.

Podemos começar a vislumbrar o perfil educador de Eliseu Coroli, que em Bragança queria tão somente ajudar no crescimento do povo que lhe foi confiado, em fé e em educação, assim como em outras obras que ele criou nos anos de sua atuação, conseguindo tudo com uma ação política conveniente à época. Em contraposição à lógica estabelecida por parte significativa da população bragantina, e amparados pelo que escreve Raymundo Heraldo Maués, podemos afirmar que os padres abominaram "a ignorância religiosa" dos caboclos. Atuaram de forma a desmontar e criar outra lógica sobre a cultura popular, conseguindo reforço na autoridade e dominação ideológica educacional e mantendo a sua intervenção, sobretudo no benefício à elite e à classe média bragantina, seja quando edificaram obras e patrimônios físicos, seja quando apresentaram sua proposta de salvação cristã (SILVA et al, 2012, p. 112-113, grifo nosso).

Com efeito, Maués (1999) aponta que as incursões missionárias pela Amazônia procuravam superar a ignorância religiosa dos índios que, desprovidos de civilidade, necessitavam ser educados. Nesse sentido, nota-se novamente a tentativa de imposição cultural da Igreja Católica sobre as comunidades indígenas da Amazônia Paraense. Como resultado obteve-se a expansão da fé cristã pelo território da Prelazia, mas também a interferência da cultura europeia nos costumes e tradições desses povos que passaram a ser domesticados no tocante a sua organização social, formas de vida e expressões da espiritualidade.

Nonato da Silva e Oleto (2010, p. 26) afirmam que os padres barnabitas, incluindo Dom Eliseu Maria Coroli, "[...] desejavam salvar os caboclos de toda forma de analfabetismo, principalmente do conhecimento de Deus e da religiosidade". Essa forma de imposição cultural se reflete na representação estereotipada de determinados grupos étnico-raciais, principalmente, ao serem considerados destituídos de civilização e cultura (MUNANGA, 2004). Por meio dessa visão grupos hegemônicos justificam a necessidade de intervenção nesses grupos que, na maioria das vezes, acaba incidindo na violação de sua cultura e identidade (HASENBALG, 1979; HALL, 2001; CANDAU, MOREIRA 2008; CARONE, BENTO, 2014).

A despeito dessas questões, não se objetiva minimizar a atuação de Dom Eliseu Maria Coroli, mas apenas problematizar que sua proposta de educação e formação de professores condizia com o contexto social e político da época que, como verificado nos estudos de Villela 
(1992), Tanuri (2000), Coelho (2006), Santos (2009), entre outros, silenciava a questão étnico-racial ou não a tratava adequadamente no sentido de reconhecer e valorizar sua cultura, história e memória. Essa questão era silenciada, pois a cor era invisibilizada nas relações sociais e nas propostas curriculares dos cursos de formação docente (COELHO, 2006).

Depreende-se, portanto, que as fontes iconográficas - fotografias - do Memorial Dom Eliseu Maria Coroli registram episódios importantes para a educação e a formação de professoras do Instituto Santa Teresinha e da Escola Normal de Bragança-PA. Contudo, não expressam as relações étnico-raciais na proposta curricular e nas práticas formativas, corroborando para a afirmação da ausência da questão étnico-racial nos cursos de formação de professores. Ademais, as fotografias colaboram significativamente para a compreensão dos processos formativos no âmbito educativo e espiritual dessa instituição, revelando não só os aspectos pedagógicos, mas os aspectos morais e religiosos desse período.

\section{CONSIDERAÇÕES FINAIS}

Esse estudo objetivou analisar a emergência da Escola Normal em Bragança-PA e sua proposição para a formação de professoras e as relações étnico-raciais entre os anos de 1938 e 1960, referentes ao ano de fundação do IST até a segunda década de sua implantação.

A proposta de educação e de formação docente de Dom Eliseu Maria Coroli compreendia quatro direções, a saber: catequese, educação escolar, assistência hospitalar e evangelização dos índios, comprovadas em seus empreendimentos e nas viagens missionárias realizadas no interior da Prelazia, sobretudo, em comunidades indígenas da região.

Depreende-se que Dom Eliseu buscou desenvolver uma formação escolar e espiritual, no sentido de uma educação geral, correlacionado, indubitavelmente, a educação e a religião como pilares de seu ministério, trabalho docente e trabalho eclesiástico.

Destarte, verificou-se na Escola Normal de Bragança-PA um fato que ocorria em todo o Brasil e Europa: o processo de feminização do magistério, especialmente na formatura da primeira turma de normalistas que se compunha majoritariamente de mulheres e apenas um homem matriculado. Nessa instituição formavam-se mulheres comprometidas com a Fé e preparadas para lecionar no ensino primário e atuar na catequização da Prelazia, moldadas também para o cuidado do lar e dos filhos, tementes a Deus e submissas aos seus maridos, conforme preconizavam a doutrina católica e os costumes da época.

Desse modo, compreende-se a relevância do IST e da Escola Normal para o desenvolvimento local, pois inseriram a instrução primária, secundária e a formação de professores, corroborando ainda na educação da população bragantina com base na Fé e na doutrina católica. Mais que instituições de ensino, configuraram-se como centros de formação escolar e espiritual pautadas nos interesses da Prelazia no sentido de preparar gerações para uma vida de devoção a Deus e moralmente exemplar, cumprindo o lema da instituição, construindo saberes, experiências e identidades.

No entanto, a questão étnico-racial não fazia parte da proposta de educação e de formação docente instaurada por Dom Eliseu, assim como ocorrera em todas as regiões do estado do Pará, permanecendo ausente no debate político e educacional e, consequentemente, nas propostas curriculares e formativas para a formação de professores da Escola Normal. 


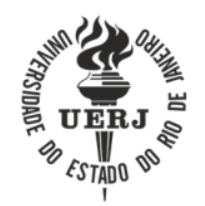

DOI: $10.12957 /$ teias.2022.61878

\section{REFERÊNCIAS}

BOURDIEU, Pierre. Regras da arte: gênese e estrutura de campo literário. Tradução de Maria Lúcia Machado. Campinas: Companhia das Letras, 2010.

BRITO, Daniel Chaves de. A modernização da superfície: Estado e desenvolvimento na Amazônia. Belém: UFPA/NAEA/PDTU, 2001.

BURKE, Peter. A Escola dos Annales (1929-1989): a Revolução Francesa da historiografia. São Paulo: Editora UNESP, 1997.

CANDAU, Vera Maria; MOREIRA, Antônio Flávio. (org.). Multiculturalismo: diferenças culturais e práticas pedagógicas. Petrópolis: Vozes, 2008.

CARONE, Iray; BENTO, Maria Aparecida Silva. Psicologia social do racismo: estudos sobre branquitude e branqueamento no Brasil. 6. ed. Petrópolis: Vozes, 2014.

CHAVES, Taylon Silva; SANTOS, Raquel Amorim dos Santos. Relações Étnico-Raciais e Lei n. ${ }^{\circ}$ 10.639/2003: Entre textos e discursos de documentos oficiais sobre legislação educacional do Estado do Pará e da Amazônia Bragantina (2003-2017). Revista da Associação Brasileira de Pesquisadores/as Negros/as (ABPN), v. 11, n. 28, p. 196-222, 2019.

CHAVES, Taylon Silva; SANTOS, Raquel Amorim dos Santos. Relações Étnico-Raciais: breve incursão sobre a Lei n. ${ }^{\circ}$ 10.639/2003 e seus desdobramentos nos discursos de documentos oficiais. [In]: MONTEIRO, Solange Aparecida de Souza (org.). A educação em suas dimensões pedagógica, política, social e cultural 4. Ponta Grossa: Atena Editora, 2020.

COELHO, Wilma de Nazaré Baía. A cor ausente: um estudo sobre a presença do negro na formação de professores-Pará (1970-1989). Belo Horizonte: Mazza Edições; Belém: Editora Unama, 2006.

COLARES, Terezinha. O Missionário Feliz: Paragominas: Gráfica e Editora São Marcos, 1997.

FRANÇA, Maria do Perpétuo Socorro Gomes de Souza Avelino de; FRANÇA, Samara Avelino de Souza. Colégio Nossa senhora do amparo: casa de oração, educação e trabalho. Revista HISTEDBR On-Line, v. 11, n. 43e, p. 175-186, 2011.

GATTI, Bernardete Angelina. Formação de professores no Brasil: características e problemas. Educação \& Sociedade, v. 31, n. 113, p. 1355-1379, 2010.

GATTI, Bernardete Angelina. Formação de professores: condições e problemas atuais. Revista internacional de formação de professores, v. 1, n. 2, p. 161-171, 2016.

GOMES, Nilma Lino (org.). Práticas pedagógicas de trabalho com relações étnico-raciais na escola na perspectiva da Lei n. ${ }^{\circ}$ 10.639/2003. Brasília: Ministério da Educação; Unesco, 2012.

HALL, Stuart. A identidade cultural na pós-modernidade. Tradução de Tomaz Tadeu da Silva. Rio de Janeiro: DP\&A editora, 2001.

HASENBALG, Carlos Alfredo. Discriminação e desigualdades raciais no Brasil. Rio de Janeiro: Graal, 1979.

LOBATO, Vivian da Silva. O Instituto Estadual de Educação do Pará-IEEP na memória de alunas e professoras (1940-1970). Tese (Doutorado em Educação: Psicologia da Educação). Pontifícia Universidade Católica de São Paulo, 2010.

LOURO, Guacira Lopes et al. O corpo educado: pedagogias da sexualidade. Belo Horizonte: Autêntica, 1999.

LOURO, Guacira Lopes. Gênero, sexualidade e educação: das afinidades políticas às tensões teórico-metodológicas. Educação em Revista, s/v, n. 46, p. 201-218, 2007. 
LUCKESI, Cipriano Carlos. Filosofia da Educação. 24. reimpressão. São Paulo: Cortez, 2010.

MAUÉS, Raymundo Heraldo. Uma outra "invenção" da Amazônia: religiões, histórias, identidades. Belém: CEJUP, 1999.

MINAYO, Maria Cecília de Souza. Pesquisa Social: teoria, método e criatividade. 19. ed. Petrópolis: Vozes, 2001.

MORTATTI, Maria do Rosário Longo. História dos métodos de alfabetização no Brasil. In: Conferência proferida durante o Seminário "Alfabetização e letramento em debate", promovido pelo Departamento de Políticas de Educação Infantil e Ensino Fundamental da Secretaria de Educação Básica do Ministério da Educação, realizado em Brasília. 2006.

MORAIS, Renant Araújo. A Escola de Primeiras Letras no Brasil Império (1822-1889): Precariedade e Exclusão. Plures Humanidades, v. 18, n. 2, p. 127-142, 2017.

MUNANGA, Kabengele (org.). O negro na sociedade brasileira: resistência, participação e contribuição. Brasília: Fundação Cultural Palmares-Ministério da Cultura, 2004.

NOGUEIRA, Juliana Keller; SCHELBAUER, Analete Regina. Feminização do magistério no Brasil: o que relatam os pareceres do Primeiro Congresso da Instrução do Rio de Janeiro. Revista HISTEDBR On-line, s/v., n. 27, p. 78-94, 2007.

NONATO DA SILVA, Dário Benedito Rodrigues; OLETO, Leila do Socorro Rotterdan. Intrépido e incansável: a atuação educacional de Eliseu Coroli em Bragança-Pará na primeira metade do século XX. Revista Veredas da História, v. 3, n. 2, p. 1-36, 2010.

RABELO, Amanda Oliveira; MARTINS, António Maria. A mulher no magistério brasileiro: um histórico sobre a feminização do magistério. In: VI Congresso Luso Brasileiro de História da Educação. Minas Gerais: Anais do evento, 2006, p. 6167-6176.

SANTOS, Raquel Amorim dos. (In) visibilidade negra: representação social de professores acerca das relações raciais no currículo escolar do Ensino Fundamental em Ananindeua (PA). Dissertação (Mestrado em Educação). Universidade Federal do Pará, 2009.

SANTOS, Raquel Amorim dos. Ciclo de Politica Curricular do Estado do Pará (2008-2012): a enunciação discursiva sobre relações "raciais". Tese (Doutorado em Educação). Universidade Federal do Pará, 2014.

SAVIANI, Dermeval. Escola e democracia. 38. ed. Campinas: Autores Associados, 2006.

SAVIANI, Dermeval. Formação de professores: aspectos históricos e teóricos do problema no contexto brasileiro. Revista Brasileira de Educaşão, v. 14, n. 40, p. 143-155, 2009.

SCHWARCZ, Lilia Mortiz. O espetáculo das raças: cientistas, instituições e questão racial no Brasil, 1870-1930. São Paulo: Companhia das Letras, 1993.

SILVA Jr., Elton Luís da. Relações Étnico-Raciais, Saber Historiográfico, Saber Histórico Escolar no curso de bistória da Universidade Federal do Pará, campus de Bragança. Dissertação (Mestrado em Linguagens e Saberes da Amazônia). Universidade Federal do Pará, 2019.

SILVA, Dário Benedito Rodrigues Nonato da; OLETO, Leila do Socorro Rotterdan; OLIVEIRA, Romyel Dillan Cecim de. Aos "caboclos inocentes e de boa fé": entre educação e outras obras de Dom Eliseu Coroli, em Bragança (PA), século XX. Revista HISTEDBR On-Line, v. 12, n. 48, p. 93118, 2012.

SOUSA, Celita Maria Paes de. Casa das Educandas ou Recolhimento das Educandas: Instituição para meninas desvalidas no Pará, no século XIX. Revista HISTEDBR On-Line, v. 11, n. 43e, p. 224234, 2011. 
DOI: $10.12957 /$ teias.2022.61878

TANURI, Leonor Maria. História da formação de professores. Revista Brasileira de Educação, s/v, n. 14, p. 61-88. 2000.

VILLELA, Heloisa de Oliveira Santos (1992). A primeira escola normal do Brasil. In: NUNES, Clarice et al (org.). O passado sempre presente. São Paulo: Cortez, 1992.

VILLELA, Heloísa de Oliveira Santos. Da palmatória à lanterna mágica: a Escola Normal da Província do Rio de Janeiro entre o artesanato e a formação profissional (1868-1876). Tese (Doutorado em Educação). Faculdade de Educação da Universidade de São Paulo, 2002.

Submissão em agosto de 2021

Aprovação em fevereiro de 2022

\section{Informações sobre autores}

Raquel Amorim dos Santos

Doutora em Educação, Professora da Universidade Federal do Pará (UFPA), Faculdade de Pedagogia

(FAPED), Campus Universitário de Castanhal. Docente do Programa de Pós-Graduação em Linguagens e Saberes na Amazônia (PPLSA), Campus Universitário de Bragança/UFPA.

E-mail: rakelamorim@yahoo.com.br

ORCID: http://orcid.org/0000-0003-4817-0036

Link Lattes: http://lattes.cnpq.br/3387666784015912

Taylon Silva Chaves

Especialista em Psicopedagogia. Graduado em Pedagogia pela Universidade Federal do Pará (UFPA).

Coordenador Geral da Educação de Jovens e Adultos da Secretaria Municipal de Educação de Peixe-

Boi/PA.

E-mail: chaveseduc@gmail.com

ORCID: https://orcid.org/0000-0003-0090-3974

Sérgio Bandeira do Nascimento

Graduado em História. Doutor em Educação, Professor da Universidade Federal do Pará (UFPA),

Faculdade de Educação e Ciências Sociais (FAECS), Campus Universitário de Abaetetuba.

E-mail: sergbandeira@ufpa.br

ORCID: https://orcid.org/0000-0002-1366-5760

Link Lattes: http://lattes.cnpq.br/7040227647321399 